\title{
RANDOM QUOTES
}

It works! I am astonished!

A spectral type is a spectral type is a spectral type.

I don't favor one way or another.

It's not very easy to change hardware when it works.

I think I have forgotten something -- my talk.

You don't know your new husband! So, you don't know all the spikes he has! It's so exciting to have a new husband ......

I have not said anything important, yet.

The use of large telescopes makes this problem more accute.

To find a single star is more difficult than you might think.

I don't like to use a lamp.

Never meddle in the affairs of specialists.

One half of a tenth arc millisecond.

Fekel does speckle.

I can see emission spikes! I can see them from here!

What we do, in two words, is to use ....... (three minutes of additional explanation).

The interstellar astronomers.....

Around the Sun there are other suns....

Perhaps we should go back to the Babylonian method - clay tablets!

Probably their pinhole is not perfect. 